\title{
The paradigm shift in intercultural communication in digital space
}

\author{
Lyubov Cherkasova ${ }^{1 *}$ \\ ${ }^{1}$ Rostov State Transport University (RSTU), Rostovskogo Strelkovogo Polka Narodnogo \\ Opolcheniya Sq., 2, Rostov-on-Don, 344038, Russia
}

\begin{abstract}
The paradigm of intercultural communication has changed its vector orientation in a period of digital space expansion. Previously existing behavioral patterns, which included basic components, have led to the emergence of new behavioral patterns through the development of high-tech production, the media industry and media space. The functional approach made it possible to identify the strengths and weaknesses of digitization, the specifics of communication space in the spheres of science, technology and education and to predict possible changes in intercultural communication on the basis of the developing digital platform. The standardization and unification of digital space, which have penetrated all spheres of human activity, have revealed opportunities for improving digital content and its knowledge component. The study reflects the features of implementation and functioning of high-tech digital equipment in the education system, which is a basic component for the formation of the man of a new generation, capable of living in digital space, managing this space, finding creative solutions and creating opportunities for further development of society. Digitization changes social consciousness completely, intensifies the gap between the older and the younger generation, but this process is inevitable, as it opens up prospects for the development of the world community and forms conditions for its unification and improvement.
\end{abstract}

\section{Introduction}

In connection with the global pandemic and the digitization in all social spheres, communication processes have gained not only an accelerated pace of the realization of a communicative act but also greater opportunities for their implementation. The relevance of information objectively determines its accelerated transfer to the communicant and interdisciplinary connections ensure the transmission of knowledge from one field to another. The exchange of information takes place instantaneously and forms a tolerant discourse that is independent of sociopolitical and administrative structures $[1,2]$. The expansion of media capabilities and media space has created a special media area of intercultural communication where changes affecting its vector quantities have begun and are developing now.

\footnotetext{
${ }^{*}$ Corresponding author : cherkasovaln@yandex.ru
} 
The paradigm shift in intercultural communication is related to the fact that electronic systems are penetrating not only technological processes but also the human being himself. It stems from the emergence of digital globalization and the multilevel introduction of new technologies into production, economic, sociopolitical, and domestic processes. While digitization in the production sphere is gradual and accompanied by increased efficiency, the sociopolitical sphere is linked to media space and media opportunities, which are even more implemented in the household sphere.

The symbolic or coded format of communication has long attracted researchers dealing with the intergenerational transmission of knowledge [3-5]. However, it was the identification of the possibility of superimposition of new concepts on concepts already known to man that became the starting point for understanding the process of intercultural communication[6]. On the basis of existing patterns of human behavior in the communicative process, we highlight the emerging new behavioral patterns in which man is becoming less and less involved, leaving a constantly increasing range of actions for machines: robots, computers, various mechanisms.

The process of transition and penetration of new information into a new communicative space takes place at both physiological and psychological levels [7]. It occurs differently in various spheres of human activity and in different age categories[8]. Communication of specialists in various spheres of human activity is carried out on the basis of data, which is a digital duplicate for specialists of the new language environment. The integration of this information depends on how well the receiving communicator is prepared to accept it [9]. Adults perceive the transmitted information as objective and have no doubt about its truth. The symbolic relationship between sent and received information, as a rule, coincides, as it includes data that has been tested, proven, or needs verification.

This is an essential prerequisite for the production sector, in which specialists can solve problems using terminology that is often derived from Latin or Greek roots. For example, medical professionals in different countries almost completely understand professional information when using special Latin terms to define and name any concept or phenomenon related to the medical sphere. Specialists in technical fields work together with linguists to develop specially prepared terminological bases, glossaries and standards. This can help to avoid inconsistencies and inaccuracies in intercultural communication.

The paradigm shift in intercultural communication that began in the productive sector has affected all spheres of human activity. However, the education portal, which is the most vulnerable in terms of digital literacy and material resources, has become the communications field that ensures the formation of a new generation capable of living in the digital space and managing it and being able to use the digital product. The standardization of educational programs aims at meeting not only the objectives of educational activities but also the organization of a communication process in accordance with the digital principle of its organization.

In this area, we highlighted the opposite sides of the formation of standardized programmatic learning. Positive aspects include the wide scope for the use of unlimited communication and professional knowledge. The negative sides are the disruption of communication between people, the reduction of personal cognitive activity, the negative impact on health and the reduction of immunity, and the deprivation of human's natural ability to resist. Humans are beginning to perceive automation and standardization as the norm, as the only possible behavioral pattern. However, the discovery of new human behavior patterns has also shown the weaknesses of human communication with robotic or mechanized equipment and machinery $[10,11,12]$. The high technologies available to the mass consumer have limited human communication.

Presenting data in digital format is a time-consuming but realistic process. It is more difficult to build 'human-robot' communication because a robot lacks emotion, empathy, 
personal experience, and personality itself. Modeling according to artificially accepted standards becomes the norm for a personality, that has to be oriented towards virtual culture and communication as opposed to human nature [13-17].

The distinction in intercultural communication in the humanities and production sphere is based on the different functionality of digital content. This difference is expressed in the fact that the solution of educational tasks takes place outside the digital platform. The digital format can only reflect the organizational system and the results of its educational process, but the creation of a literate person or a professional in the production field can be represented in numbers only in theory. However, the digital principle is effective in presenting material in digital form, as well as in using digital space for searching information and implementing a communicative act.

In contrast to intercultural communication in humanities, the digitization of production communication spaces completely changes the communication process. In intercultural communication, this means the opportunity to solve complex problems and exchange information directly while they are being solved. .

\section{Materials and methods}

The synthesis of pragmatic and comparative approaches to the presented material allows us to use hypothetical and deductive methods. Based on the analysis of human communication capabilities in society and their transformation due to mass digitization, we carry out analogy and reveal features, positive and negative phenomena of intercultural communication in digital space. Applying such methodological approaches as functional, explanatory and critical, we have identified several behavioral patterns, which form the standard model of a person in the information space, identified new emerging behavioral patterns, and predicted the further development of behavioral patterns in the future. The analysis was carried out taking into account individual and age differences in human beings, their nature, behavior, and knowledge.

\section{Results}

For a long time, cognitive scientists have not paid enough attention to communicative mechanisms, despite the fact that they are the ones that transmit cultural values from generation to generation through signs or labels. Overlaying new concepts on already understood and familiar concepts turns the process of perception, reasoning and socializing into an easily implementable process of communication. This is especially true of complex behavioral patterns that differ by the locality of functioning. Their mode of implementation and effectiveness vary depending on the sociocultural space in which they are located.

In modern society, intercultural communication has long been based on three main models in which human participation is indispensable [3]. However, the development of new technologies and the emergence of high-tech equipment have given a person the opportunity to carry out constant communication activities, regardless of the conditions and locality. Digital equipment, which has replaced or partially replaced humans in many areas, has caused the beginning of the formation of new behavioral patterns in the social space. The implementation of these models in society reflects a pragmatic approach to the digital transfer of knowledge from one communicator to another. 


\subsection{Discussion. Models of intercultural communication}

Apart from such communicative structures as "man-man", "man-society" or "mansociety-man", digital space forms an additional "man-machine" structure, in which communication until now is less free than in structures where people are involved in bilateral order. Communicating with a machine constrains humans, depriving them of the freedom to express their emotions and to react vividly [9].

Human nature resists standardized phrases and actions because each person is different. Everyone has a unique set of physical and physiological abilities, his own chosen moral guidelines and norms. This set determines a person's approach to the communicative process and behavior in familiar, unfamiliar or new situations.

Intercultural communication in digital space changes the role of man and his position. The person becomes part of "man-machine" system, so the previously existing variants of the human behavioral pattern in the communicative process also undergo changes. It is more accurate to say that these patterns are developing and their number is increasing.

It is necessary to familiar and ordinary in the 21 st century "man-man", "man-society" and "man-society-man" models to add new models, in which man is involved to a lesser extent or not at all. The human being ceases to be the obligatory unit that is the root cause of everything. Information and informative data are coming to the fore. They are expressed in numbers, with which society seeks to measure everything: economic profits, losses or risks, production achievements, costs and losses, the sociopolitical and personal activity of individuals and groups, the effectiveness of events, competitions, and even health and art.

Data and information are also at the core of the integrated production environment. Information is the digital twin of the production environment, which is integrated into any field of activity and enables communication between professionals of different linguistic environments [2]. However, the relevant informative content has long gone beyond the production environment. From the beginning, information technology has filled and greatly expanded the domestic sphere of intercultural communication and then began to be introduced into other areas of productive, economic and recreational activities.

The next signs of a paradigm shift in intercultural communication are behavioral models such as "man-man with an implanted artificial mechanism", "society-man with an implanted artificial mechanism", "mechanism-man with an implanted artificial mechanism".

It is logical to assume the emergence in the near future of models, in which humans do not participate. This possibility excludes the very existence of the human being in a digitally redundant society, in which intercultural communication becomes an interaction of mechanisms.

This can occur on a personal basis or it can take on a mass character. In the first case, man loses contact with society, ceases to respond to the surrounding reality and to define himself as an individual In the second case, the mass character of the escape into virtual reality devalues the existence of society itself.

Intercultural communication presupposes the interaction of cultures, in which a person, opposing and comparing himself with other criteria and values, chooses the aspects that correspond to his life principles and are not dissonant with his life position.

The informatization of society, the growth of multimedia products and the increase in visual space create the basis for the dominant role of the media sector: communication and information exchange takes place directly during contact, which people can establish regardless of distance, different political beliefs and clerical postulates. The transformation of intercultural communication leads to a partial modification of world cultures, weakening a person's connection to the original national culture.

Fig. 1 presents new and projected human behavior patterns in digital intercultural communication that reflect the future development of digitization, partially replacing a 
person in the communicative space or completely excluding a person from participation in social life and communication process. The picture shows that the transition from the "manman" model takes place through the "man-society" model. Then a machine can be introduced into the model, which, in turn, becomes a single unit with a human being with an implanted artificial mechanism, subsequently, it can replace the human being completely.

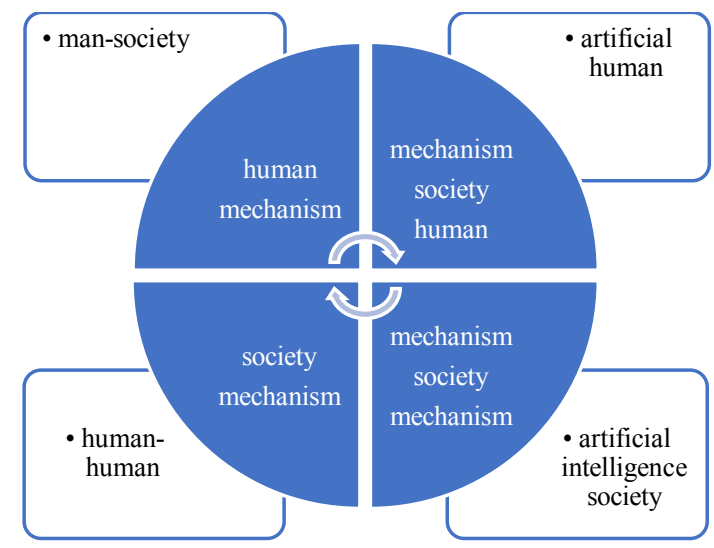

Fig. 1. Human behavioural patterns.

\subsection{The negative side of the paradigm shift in intercultural communication}

The massive implementation of digital technology also has negative consequences because it provokes higher levels of cyber aggression in children and young people [13]. The emotional stress of young Internet users, based on suddenness and risks combined with high personal interest, at the same time decreases the effectiveness and level of acquired knowledge. The excess and unlimited consumption of digital content and its components and the perception of communication flows can be controlled either by explaining possible risks and negative health effects or by setting new goals and motivational activities outside the digital space.

This approach works differently with different age groups. While minor children rarely take adults' words as true, resisting their demands, teenagers, whose communication space is more filled with important to them events, meetings with friends, opportunities to see more and learn more, are more likely to agree with adults. However, both groups are guided by their own interests, hobbies and pleasures.

The theoretical notion that young people will try to gain knowledge on their own in digital space makes us doubtful of their quick success. There are too many temptations for a young person, whose personality is not yet fully formed or overly influenced by the external environment, both online and in an independent approach to the choice of activities and material. This is not the case if parents or adults, educators or older relatives have been able to raise in their child a high-risk perception, acceptance of advice and rules for using the Internet.

Nevertheless, different generations perceive cognitive data through digitization in different ways: they vary in speed, efficiency, duration of information assimilation. Young people are quick to adapt to rapidly changing gadgets, they easily switch from one model to another. New gadgets and mechanisms do not frighten them with their multi-level programs and complexity of control. Children and adults have different perception speeds. Younger children are slower to perceive information, but they are quicker to learn how to use it. Perception depends on the interest in the information that has been developed or has been 
aroused. In addition, communicative information is transferred to the younger generation with a delay [1]. All this causes an increase or decrease in information perception and an uneven comprehension by adults and children and, as a result, an increase in the risk of misunderstanding.

Table 1. Modern changes in the paradigm of intercultural communication.

\begin{tabular}{|c|c|}
\hline \multicolumn{2}{|c|}{$\begin{array}{l}\text { Changes in intercultural communication } \\
\end{array}$} \\
\hline $\begin{array}{l}\text { Reasons for changes in intercultural } \\
\text { communication }\end{array}$ & $\begin{array}{l}\text { Methods to improve the effectiveness of } \\
\text { intercultural communication }\end{array}$ \\
\hline Revaluation of cultural property. & $\begin{array}{l}\text { Identification and explanation of the historical } \\
\text { reasons for the revaluation of cultural values. }\end{array}$ \\
\hline $\begin{array}{c}\text { Differences in the communicative behavior of } \\
\text { partners. }\end{array}$ & Interculturalism and knowledge of other cultures. \\
\hline $\begin{array}{l}\text { Variability of regulatory methods of } \\
\text { information flows. }\end{array}$ & $\begin{array}{l}\text { Development of the competence to search for the } \\
\text { necessary information. }\end{array}$ \\
\hline Mismatch of directions of information flows. & $\begin{array}{l}\text { Developing the competence for the selection of } \\
\text { the necessary information. }\end{array}$ \\
\hline Different speed of information transfer. & $\begin{array}{l}\text { Development of competence in working with } \\
\text { new technological devices. }\end{array}$ \\
\hline $\begin{array}{l}\text { Insufficient knowledge of the verbal and non- } \\
\text { verbal norms of a foreign culture. }\end{array}$ & $\begin{array}{l}\text { Knowledge of traditions, verbal and non-verbal } \\
\text { norms and cultural values of other peoples. }\end{array}$ \\
\hline $\begin{array}{l}\text { Different decoding of behavioral norms in } \\
\text { different linguocultures. }\end{array}$ & $\begin{array}{l}\text { Knowledge of the necessary information about } \\
\text { the behavioral norms of other peoples. }\end{array}$ \\
\hline $\begin{array}{c}\text { Egocentrism and negative attitude towards } \\
\text { objects of another culture. }\end{array}$ & Educational activity. \\
\hline $\begin{array}{l}\text { Formation of primitive images of } \\
\text { representatives of different cultures and } \\
\text { stereotyping of ethnic consciousness. }\end{array}$ & $\begin{array}{c}\text { Expanding ethnic and historical knowledge of } \\
\text { other cultures. }\end{array}$ \\
\hline Prejudice. & Analysis of historical background and events. \\
\hline Sensual perception of information. & Developing an objective assessment of events \\
\hline $\begin{array}{l}\text { Incomplete or inaccurate information about } \\
\text { the identity of the partner. }\end{array}$ & $\begin{array}{l}\text { Development of competence for obtaining } \\
\text { reliable information about a partner. }\end{array}$ \\
\hline $\begin{array}{l}\text { Internet communication. Virtual } \\
\text { communication. Web communication. Online } \\
\text { communication. Electronic communication. }\end{array}$ & $\begin{array}{l}\text { Improving communication skills on various } \\
\text { Internet platforms. }\end{array}$ \\
\hline
\end{tabular}

Cognitive data has shown that even the differentiation of vowel sounds pronounced by native speakers has a great impact on the vocabulary of a child or future social communicator [6]. Therefore, communicative efficiency is reduced when communicating with people who have various phonetic features or accents that are typical for speakers of different nationalities. For example, the pronunciation of Latin Americans speaking Russian is characterized by a whistling ' $\mathrm{s}$ ' sound and a less degree of vowel reduction. English-speaking Indians have a softer pronunciation of ' 1 ' sound, absence of aspiration of some sounds and a changed to a vibrant ' $r$ ' sound. The digital representation of material in education allows this or similar circumstance to be excluded from communicative content and increases communicative efficiency.

Thus, it can be argued that the paradigm shift in intercultural communication should be taken seriously by observing how necessary or undesirable this virtual contact is. It all determines the type of digital behavior of the participant in digital communication and his dependence on a digital device. 


\section{Discussion. The paradigm of intercultural communication in education}

The change in the paradigm of communication, the expansion of its space, the reorientation of its vector towards digital content have revealed not only new opportunities for educational programs but also the strengths and weaknesses of education, which is the basis for the establishment of social institutions and structures. Educational programs, aimed at preparing a person to live in the digital space, are a set of measures designed to create a situation of free choice. However, any choice depends on the set of skills and knowledge that a person possesses.

In order to search for the necessary information a person has to navigate several related fields of information. To choose information it is necessary to know what is required in a given situation. The digital space has expanded rapidly due to the multiplicity of media that have emerged. The media industry through mass communication and information media has created its own media discourse, in which the functional laws of operation have not been worked out yet.

A person transfers paradigmatic principles to existing knowledge content and applies them to new conditions. For example, whereas in the past ordinary digital cards were used mainly to extend the vocabulary of students when learning a foreign language, the introduction of grammar flashcards into the learning process confirms the effectiveness of the numerical and digital perception of information [10]. This is only a single example of the digitization of knowledge, but the current trend to transfer all information to a digital platform assigns challenging and expensive tasks for a person to ensure the digitization process, and also reflects the weaknesses of preparing the younger generation for life in the digital world.

\subsection{Comparative analysis of intercultural communication in society, production and science}

The integration of communication competence into information literacy takes place not only in the educational academic environment but also in the general social environment, which in turn is subdivided into a lot of social and productive groups. Communicative competence, which is the result of this integration, ensures the communication of people in different spheres.

The transdisciplinary nature of communicative competence is the basis for human communicative activity in both digital space and off-line communication. However, new technologies significantly expand communicative capabilities by creating their own semantic network with constituent components linked by special relations, which are implemented through special tools and methods [4].

Although digitization initially embraced the production sphere, then it became widespread in sociopolitical communication. Its active use and application in the domestic sphere have taken place in a short period. Short time frame has been a serious test for older people with good experience and practical skills, but who are not always ready for the natural perception and acceptance of numerous gadgets that are managed by their children or grandchildren quickly and skillfully.

Fig. 2 shows in which areas and to what extent the digital principle of intercultural communication is used. Digitization began in the production and economic spheres and then spread to the sociopolitical and domestic spheres. However, the degree of digitization of these areas has been diametrically reversed: the use of high technology has become widespread at home. This has occurred as a result of the expansion of media space through mobile communications capable of providing high-tech instant communications. The extent 
of each sphere expansion is constantly changing. It is not researched well and requires more statistics. Nevertheless, highlighting the constituent components of these spheres limits each of them to the scope and functional approach of this classification.

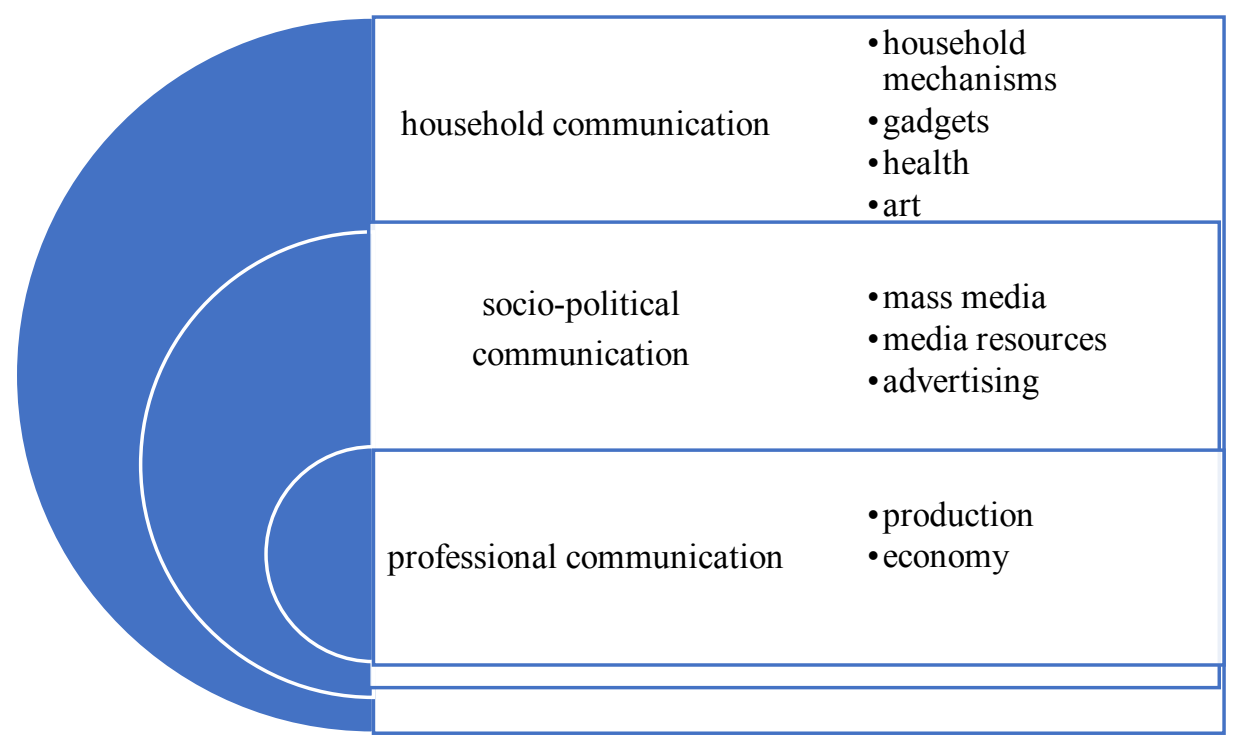

Fig. 2. In which areas and to what extent the digital principle of intercultural communication is used.

IT technologies, which are at the heart of rapidly developing digitization, have defined the central points of communication. These are cloud-based centers or entire cloud systems in which it is possible to exchange information, alter a program code, or transform action algorithms. And also this program can be adjusted to respond to possible challenges and risks.

The digital technologies that form the new digital space make it possible to solve unexpected problems quickly on the basis of the analytical data that a person prepares, guided by his own mind, reaction and action [5]. Intercultural communication has developed particularly rapidly on the basis of mobile communication, which, by integrating new and existing modes of communication, has been able to connect and thereby strengthen the distribution of television signals. This has made it possible to integrate the media into a single system in which news is exchanged quickly. In addition, such technical convergence has also determined the linking of journalism professionals.

Digitization in the humanities and social sciences has so far been based only on the digital representation of existing knowledge. This field does not reflect social theories of digital transformation. It represents in digital form only what man has already created, achieved or invented [9]. Thus, intercultural communication in the field of humanities involves to a greater degree an exchange of already existing information in order to learn and understand the cultures of other countries.

\subsection{Shifting the educational paradigm orientations}

The transition to digital education is not happening as fast as we want it. Not all teachers and professors have the necessary training and knowledge to deal with new technologies. Innovative methods also require cognitive updating. This requires a renewal of the entire organization of the educational system and the educational communication space, as well as the intentional use of new technologies in the educational process. 
This leads to a reorientation of the educational paradigm towards a digital platform, which in turn enables the natural perception and acceptance of digital knowledge at the cognitive level.

If earlier, the main principle of the educational process was the principle of transferring knowledge, new information, developing and improving the skills of performing certain actions. Then in this educational digital space, the formation of an independent search for information, its conscious selection, the ability to navigate in the information space and quickly learn to use the acquired knowledge becomes paramount, operating with them not only in the process of general communication, but also in a narrowly professional sphere. Instilling search skills begins long before schoolchildren: now specialists are organizing more and more digital platforms with the aim of both teaching new technologies and in order to identifying the most capable, extraordinary and creative young people. The worldwide race to create artificial intelligence sometimes seems pointless, but it is this creation determines the priority of a people or a state in a world. It is important because there are still many contradictions, hatred and cruelty. These contradictions are the reason for the emergence of a large number of opponents of world globalization and, as a result, the massive transfer of all spheres of human activity to the digital space.

In order to reduce the gap between the school and the outside world, studies have been conducted on teacher's pedagogical and technological behavior and internal organizational environment. They revealed administrative, bureaucratic and political obstacles that the educator is not prepared to overcome on his own [12].

Nevertheless, teachers' formed civic engagement has provided them with a high level of motivation and, as a result, a high degree of efficiency in the transition to the digital space of all participants in the academic process.

The motivation of students is directly related to the extent to which a teacher was able to provide or generate students' motivated activity.

However, this aspect is the weakest in Russian educational institutions. On the one hand, the change in the general cultural communicative paradigm has influenced the change in the educational paradigm, on the other hand, it is the educational paradigm that is most dependent on social, administrative and political structures.

\subsection{Media discourse as an integral and promotional component of intercultural communication}

A person's long-term stay online makes it necessary to produce the vast news content that he encounters in digital space. This determines the need for special training in working with the media space, where, like in a huge information basket, everything is packed into one device. In order to find the necessary information, you need to know methods and ways of searching it, excluding useless options and choosing the optimal way [14].

The media and social networks are closely linked: any events that occur in society are reflected in the press. However, the Internet is often ahead of traditional media, which effectiveness depends on a person and his efficiency and simultaneous reliance on the necessary action.

In this aspect, online information, which attracts the attention of a large digital audience, quickly becomes widespread. The speed of online reaction provides quick help in case of need, but it also generates an instant spread of negative information, which increases tension and becomes the basis for the formation of a stressful situation. Not everyone is able to cope with the negativity imposed by online media.

The change of communication paradigm and the constantly increasing complexity of media content is based on traditional theory and new research with permanently growing 
amounts of information data [15]. This data is put online not only by journalists and newsmakers but also by ordinary online users, most often in social contact groups.

Under the influence of the media, which reflects the goals and objectives of any social group or nation, the person himself changes, his consciousness is transformed, and some priorities are replaced by others. Media culture is increasingly becoming a basic component of intercultural communication: it is becoming the main criterion for relations emerging in the digital world; it determines the norms and boundaries of communication. However, the infinite number of information platforms, Internet sites, mobile applications and technical gadgets serving them have become the reason for the blurring of cultural and normative boundaries. This applies not only to the speech or text embodiment of communicative material, but also to the expression of any information content, often without taking into account the national and cultural characteristics of its localization. As a result, there is an aggressive influence of the media environment on a person and human consciousness in order to form public consciousness, which is necessary and convenient for a certain group of society. It is no secret that every media outlet reflects someone's interests, defends their positions, and contributes to the creation of an image and public opinion regarding this or that event, person or public order.

The development of online advertising has been especially intensive. It is presented not only on the advertiser's websites but visualized differently on various online pages [16]. Integration into the global community has opened up the problem of presenting advertising in a foreign language environment and in a different value system. However, in order to remain effective from the communication point of view, the advertising product must be presented in a form adapted to realities.

\section{Conclusions}

Intercultural communication, implemented in different aspects, is practically realized in interdisciplinary relations [17], which are based on its urgency and relevance in the new communication paradigm. The communicative paradigm reflects the phenomenon of mutual knowledge transferring from one field of knowledge to another and enables the exchange of this knowledge within the same knowledge competence.

The implementation of communication processes in the modern world has specific features: the ability to solve communication problems in the digital space increases the isolation of a person, deprives him of social ties, inhibits the development of a social personality, which can exist and develop only in society. Information exchange between people is a necessary stage of a communicative act, a stage of cognition, rising to which a person learns new skills, acquires new abilities, improves and develops as a social person. Communicative connections, criteria and opportunities, which are the basis for the intensification of social transformations and the economic system of this society, at the same time, can be disrupted due to absolute digitalization, not based on human and humanitarian principles of existence. Replacing real connections between people, with their emotional content, in the digital space can lead to a devaluation of human feelings and human relationships themselves.

The need for communication in reality distinguishes Homo sapiens from other creatures. Constant information contact with society or its structural components, the exchange of information, its analysis and selection determine the social position, status and social set of skills and abilities of a person. An individual portrait of a person is formed on the basis of a personal approach to the information offered by society. Therefore there cannot be a single person completely similar in their qualities and characteristics to another person, because there are no identical characters, experiences and emotions: they are individual for each and have their own reasons and conditions of occurrence. 
In this aspect, technological improvements that form a single form of communication create a contradictory situation in which there is a discrepancy between the real fact and the necessary human need. Nevertheless, it is impossible to deny or oppose such a transformation of social relations and social transformation, because society develops cyclically according to objective laws, and new technologies that have received the opportunity to be introduced into all spheres of life cannot be canceled. It is like canceling all inventions, breaking all technical devices, forgetting about all the achievements of humankind, discarding all the knowledge accumulated over a centuries-old history. The modern position of the world community, focused on the priority of technical progress, does not rely on the moral and cultural values of the past times, does not take into account the need to preserve the priorities of humanism, respect and preserve national characteristics.

The term "elusive sociality", which has appeared in recent years, reflects the tendency to the loss of social ties between people, to individualization and isolation of the individual from society, to a loss of interest in social transformations and problems. Therefore, the problem of pragmatism of changing the paradigm of intercultural communication in the digital space is becoming more and more serious every day. The development and existence of the person himself depends on which path the development of human society as a whole will take. New technologies can become a powerful tool for improvement, but at the same time, they can serve as a means of destroying the person himself. The contradiction arising in the process of society's progress between the creative human principle and its technical and technological implementation is the criterion that determines the vector of the paradigm of intercultural communication of the future. Man, in his essence, is an inventor: throughout his entire existence, he constantly strives to simplify all physical actions available to him and to improve the mechanism of their actualization. The main thing in this is what place in this technological world is assigned to a man himself.

The digital nature of the modern paradigm of intercultural communication has also caused the emergence of tolerant discourse, which reflects the implementation of communicative action of a pair of participants. Tolerant discourse is based on communicative freedom, when its participant, following the rules of the correctness of communication, chooses himself the most appropriate option, mode and method of communication or influence on the interlocutor [18].

This principle is embedded in all standardized educational programs that determine what generation will be in the near future: whether they will be capable of human communication, love and friendship, or will be locked in their own virtual world. The behavioral patterns presented in the article show the prospects for further research into the changing processes within the intercultural communication paradigm.

However, the creation of a virtual world based on digital space can alienate a person create an illusory space in which people become individualized and may lose contact with society. If we consider that the laws of social development are cyclical and objective and do not depend on the will of a person or a group of people, then the process of globalization should be understood as an objectively necessary reality.

Nevertheless, in this process the culture, traditions and values, which each nation has developed over many centuries, become the main obstacle and condition for difficulties to arise. And they remain for many people the unbreakable foundation of their existence as a nation.

\section{References}

1 E. Kulikova, L. Brusenskaya, L. Zhebrowskaya, Media Education, 4, 508-517 (2019)

2 E. Kulikova, Media Education, 59(1), 61-72, (2019), DOI: 10.13187/me.2019.1.61 
3 C. Brand, A. Mesoudi, P. Smaldino, Trends in Cognitive Sciences (2021), ISSN 13646613, https://doi.org/10.1016/j.tics. 2021.03.002, https://www.sciencedirect. com/science/article/pii/S1364661321000589

4 P. Raj, J.-W. Lin, Advances in Computers, 117(1), 1-34, (2020), ISSN 0065-2458, ISBN 9780128187562, https://doi.org/10.1016/bs.adcom.2019.09.008. (https://www.sciencedirect. com/science/article/ pii/S0065245819300518)

5 Y. Mou, K. Xu, Computers in Human Behavior, 72, 432-440 (2017), ISSN 0747-5632, https://doi.org/10.1016/j.chb.2017.02.067.

6 V. Kolmakova, D. Shalkov, and O. Baryshnikova, In Proceedings of VIII International Scientific and Practical Conference «Innovative technologies in science and education» (ITSE 2020), 18023 (2020), https://doi.org/10.1051/e3sconf/202021018023.

7 R. Kasaba, K. Shimada, A. Tomoda, Neuroscience, 457, 206-217 (2021), ISSN 03064522, https://doi.org/10.1016/j.neuroscience.2020.12.002.

8 D. Yu. Shalkov, V. V. Kolmakova, E. S. Shilova, Lecture Notes in Networks and Systems, 198, 136-144 (2021), https://doi.org/10.1007/978-3-030-69415-9_16

9 S. M. Bazaz, M. Lohtander, J. Varis, Procedia Manufacturing, 51, 1125-1131 (2020), ISSN 2351-9789, https://doi.org/10.1016/j.promfg.2020.10.158.

10 F. García-Marco, Pathways into Information Literacy and Communities of Practice, (Chandos Publishing, 2017), ISBN 9780081006733, https://doi.org/10.1016/B978-008-100673-3.00006-X.

sciencedirect.com/science/article/pii/B978008100673300006X).

(https://www.

11 Y. Wang, A. Seidl, A. Cristia, Infant Behavior and Development, 62101524 (2021), ISSN 0163-6383, https://doi.org/10.1016/j.infbeh.2020.101524.

12 J. Serfaty, R. Serrano, System, 94, 102342 (2020), ISSN 0346-251X, https://doi.org/10.1016/j.system.2020.102342.

13 S. Roth, H. F. Dahms, F. Welz, S. Cattacin, Technological Forecasting and Social Change, 149, 119778 (2019), ISSN 0040-1625, https://doi.org/10.1016/j.techfore. 2019.119778.

14 J. C. Wiziack, V. M. P. D. dos Santos, Heliyon, 7(1), e05928 (2021), ISSN 2405-8440, https://doi.org/10.1016/j.heliyon.2021.e05928.

15 Ramos-Soler, C. López-Sánchez, T. Torrecillas-Lacave, Revista Científica de Comunicación y Educación, 26(56), 71-79, (2018).

16 S. V. Bylkova, D. Y. Shalkov, In Proceedings of VIII International Scientific and Practical Conference «Innovative technologies in science and education» (ITSE 2020) (2020), https://elibrary.ru/item.asp?id=44397209

17 D. Stanfield, L. Beddoe, Social Work Education, 35(3), 284-296 (2016)

18 K. Thorson, C. Wells, Communication Theory, 26 (3), 309-328 (2016) 